\title{
Optimasi Hyperparameter TensorFlow dengan Menggunakan Optuna di Python: Study Kasus Klasifikasi Dokumen Abstrak Skripsi
}

\author{
Siti Mujilahwati ${ }^{1}$, Miftahus Sholihin ${ }^{2}$, Retno Wardhani ${ }^{3}$ \\ Program Studi Teknik Informatika, Fakultas Teknik, Universitas Islam Lamongan, Jawa Timur, Indonesia \\ Email: 1," moedjee@gmail.com, ${ }^{2}$ miftahus.sholihin@gmail.com, ${ }^{3}$ retzno@yahoo.com \\ Email Penulis Korespondensi: moedjee@gmail.com ${ }^{1}$
}

\begin{abstract}
Abstrak-Pada era digital yang berkembang pesat saat ini peran komputasi pada kecerdasan buatan sangat dibutuhkan untuk dapat membantu para pelaku bisnis. Baik dari bidang perekonomian, Kesehatan dan juga Pendidikan. Penggunaan machine learning akan membantu pihak terkait dalam melihat, menganalisis dan mengambil keputusan. Dengan machine learning segala sesuatu permasalahan yang terkait dengan data akan dapat diselesaikan dengan cepat dan tepat. Permasalahannya adalah dokumen skripsi tiap tahun pasti semakin bertambah, akan menjadi sebuah dokumen yang sia-sia jika tidak dilakukan pengolahan data tersebut. Data skripsi yang sudah lampau dapat dijakian analisis dan pengambilan keputusan pada era skripsi berikutnya. Python merupakan salah satu Bahasa pemrograman yang populer digunakan untuk machine learning. Salah satu alasanya adalah banyaknya library yang berbasis python. Keras adalah salah satu library machine learning berbasis python. TensorFlow dapat digunakan jika berhubungan dengan pengolahan data yang banyak, termasuk data abstrak skripsi. Dengan demikian penelitian ini melakukan klasifikasi 140 dokumen abstrak skripsi dengan menggunakan keras-TensorFlow dengan tujuan bahwa berdasarkan isi abstrak tersebut akan diklasifikasikan pada 6 kelas yaitu Aplikasi Android, Data Mining, RPL, SPK, Pengolahan Citra Digital dan Sistem Pakar. Adapun hasil klasifikasi dengan data latih sebanyak 82 dokumen dengan setting model betch size $=12$ dan epoch $=2$ dengan nilai akurasi $89,04 \%$. Sedangkan pada data uji test loss memiliki nilai lebih tinggi daripada nilai akurasi yang diperoleh 66,66\%. Dengan memanfaatkan memaksimalkan kinerja TensorFlow dengan menambahkan parameter yang dimiliki scikit learn yaitu optuna. Data tes dilakukan optimalisasi dengan nilai trials sebanyak 500 akurasi meningkat menjadi $76.19 \%$.
\end{abstract}

Kata Kunci: Optimasi; TensorFlow; Optuna; Python; Skripsi

\begin{abstract}
In today's rapidly growing digital era, the role of computing in artificial intelligence is needed to be able to help business people. Both in the fields of economy, health, and education. The use of machine learning will help related parties in viewing, analyzing, and making decisions. With machine learning, all problems related to data can be solved quickly and precisely. The problem is that the thesis document will increase every year, it will become a useless document if the data processing is not carried out. Past thesis data can be used for analysis and decision-making in the next thesis era. Python is one of the most popular programming languages used for machine learning. One reason is that there are many python-based libraries. Keras is a python-based machine learning library. TensorFlow can be used when dealing with large amounts of data processing, including thesis abstract data. Thus, this study classified 140 thesis abstract documents using hard-TensorFlow with the aim that based on the abstract content it would be classified into 6 classes, namely Android Applications, Data Mining, RPL, SPK, Digital Image Processing, and Expert Systems. The results of the classification with training data as many as 82 documents with model setting batch size $=12$ and epoch $=2$ with an Accuracy value of $89.04 \%$. While the test loss test data has a higher value than the Accuracy value obtained by $66.66 \%$. By utilizing maximizing TensorFlow performance by adding a parameter that Scikit Learn has, namely Optuna. The test data was optimized with a trial value of 500, the Accuracy increased to $76.19 \%$.
\end{abstract}

Keywords: Optimization; TensorFlow; Optuna; Python; Thesis

\section{PENDAHULUAN}

Perkembangan kecerdasan buatan di era digital seperti ini dapat kita lihat dengan jelas bagaimana tumbuh dengan pesat dan sangat dibutuhkan. Baik dibidang Kesehatan, bisnis, dan juga Pendidikan. Skripsi mahasiswa, semakin tahun semakin bertingkat. Akan menjadi suatu dokumen yang sia-sia jika tidak dilakukan klasifikasi. Terutama dengan perkembangan teknologi machine learning seperti saat ini. Dengan melakukan klasifikasi dokumen skripsi, baik berdasarkan teks abstrak maka dapat diperoleh hasil analisis dari dokumen tersebut berdasarkan tujuannya. Misal analisis masalah topik skripsi mahasiswa, yang artinya akan dilakukan klasifikasi dokumen skripsi berdasarkan topik. Dapat menganalisis trend topik skripsi, dapat melakukan kecocokan abtrak dengan topik. Dan masih banyak lagi yang dapat dilakukan dengan dokumen skripsi tersebut.

Deep learning merupakan bagian dari machine learning yang dapat mengatasi pada kasus data yang besar dan semakin meningkat. Beberapa klasifikasi dokumen yang telah dilakukan pada penelitian sebelumnya menyatakan bahwa Deep learning dapat bekerja dengan baik[1], [2]. Selain itu Deep learning dapat bekerja dengan baik karena memiliki konsep bekerja secara mendalam seperti otak manusia. Klasifikasi merupakan pengelompokkan berdasarkan kelas target yang telah dilabeli sebelumnya. Beberapa penelitian yang melakukan klasifikasi dengan Deep learning lebih banyak menggunakan data gambar[3], [4]. Sedangkan klasifikasi teks dengan memanfaatkan Deep learning sering digunakan menganalisis sentiment dengan menggunakan data short teks baik dari Bahasa Indonesia, arab dan Bahasa inggris[5]-[9]. Ada beberapa algoritma Deep learning yang dapat diterapakan untuk melakukan klasifikasi gambar maupun teks diantaranya Artificial Neural Network[10], Convolutional Neural Network[11], [12], Backpropagation Neural Network[13]. Dari beberapa algoritma tersebut dapat memberikan hasil yang baik, akan tetapi ada beberapa penelitian sebelumnya juga melakukan 
optimasi dari algoritma yang digunakan seperti yang dilakukan pada optimasi algoritma Neural Network dengan algoritma genetika [14]-[18].

Dari uraian di atas serta mempelajari beberapa penelitian yang telah disebutkan, maka penelitian ini menemukan start of the art. Yaitu penelitian ini akan melakukanklasifikasi dokumen abstrak sekripsi dengan menggunakan konsep Deep learning dengan memanfaatkan kerangka TensorFlow dari data teks. Dimana pada penelitian sebelumnya banyak yang menggunakan data gambar dan sort teks. Selain itu optimasi hasil akurasi klasifikasi akan mencoba memanfaatkan library optuna di scikit learning pada python.

\section{METODOLOGI PENELITIAN}

Desain alur dari penelitian ini adalah digambarkan pada gambar 1 berikut ini.

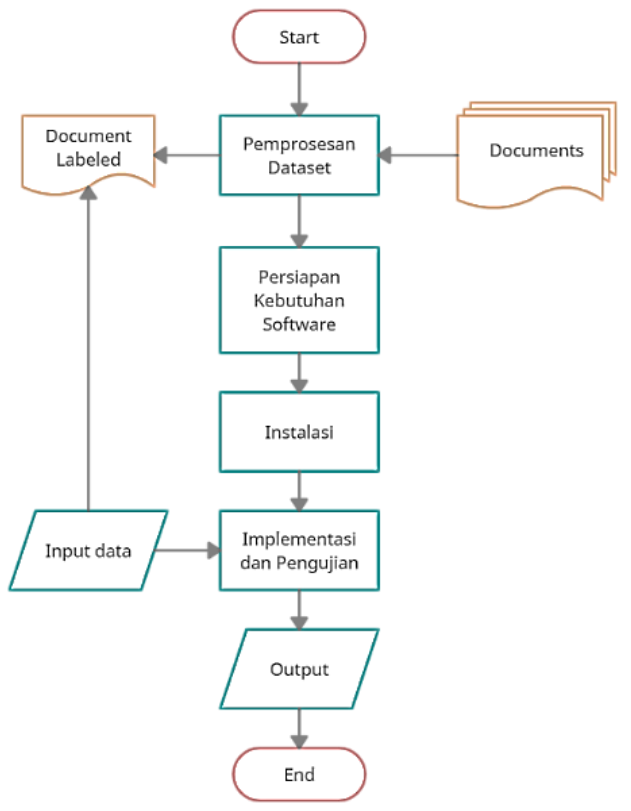

Gambar 1. Alur Penelitian

Konsep penelitian yang bersifat pengujian dan analisis pada penelitian ini, maka pertama yang dilakukan adalah:

1) Analisis Data

Data yang akan digunakan adalah data atau dokumen abstrak skripsi mahasiswa Teknik informatika lulusan 2020, dokumen yang tersimpan sebanyak 103 file. Setiap dokumen akan dilabeli dengan kelas berdasarkan topik yang dibahas. Setelah dibentuk ada 6 kelas target, dan masing-masing memiliki sebaran seperti ditampilkan pada tabel 1 berikut ini.

Tabel 1. Data Faktual Masing-masing Kelas

\begin{tabular}{lll}
\hline No & Kelas & Jumlah Dokumen \\
\hline 1 & Aplikasi Android & 38 \\
2 & Data Mining & 19 \\
3 & RPL & 16 \\
4 & SPK & 14 \\
5 & Pengolahan Citra Digital & 8 \\
6 & Sistem Pakar & 8 \\
\hline Total & & 103 \\
\hline
\end{tabular}

Data tersebut nantinya akan dilakukan pengujian klasifikasi pada masing-masing kelas dengan model Deep learning menggunakan library Keras TensorFlow di python.

2) Persiapan kebutuhan software dan library

a) Jupyter Notebook

Dalam hal ini, "notebook" atau "dokumen notebook" menunjukkan dokumen yang berisi elemen kode dan seperti teks, gambar, tautan, persamaan. Karena campuran elemen kode dan teks, dokumen ini adalah tempat yang ideal untuk menyatukan deskripsi analisis, dan hasilnya, serta dapat dieksekusi melakukan analisis data secara real time.[19]. Jupiter Notebook merupakan aplikasi edit teks untuk machine learning dan bersifat client-server. Aplikasi ini dapat menjalankan kode python.

b) Python 
Python merupakan Bahasa pemrograman yang berisifat interaktif dan dapat dijalankan diberbagai macam platform atau aplikasi. Salah satunya adalah aplikasi Jupyter Notebook. Dengan menggunakan aplikasi tersebut maka kita dapat langsung mengeksekusi setiap baris kode python. Banyak dukungan library apabila kita membuat program python untuk pengolahan data maupun machine learning. Pada penelitian ini menggunakan python versi 3.0.

c) Keras - TensorFlow

Keras merupakan API pada Deep learning pada pemprograman python dan berjalan di atas machine learning TensorFlow. Keras memiliki ciri :

Simple : tapi tidak sederhana. Keras mengurangi beban kognitif pengembang untuk membebaskan Anda untuk fokus pada bagian masalah yang benar-benar penting.

Fleksibel : Keras mengadopsi prinsip pengungkapan progresif kompleksitas: alur kerja sederhana harus cepat dan mudah, sementara alur kerja lanjutan yang sewenang-wenang harus dimungkinkan melalui jalur yang jelas yang dibangun berdasarkan apa yang telah Anda pelajari.

Powerful : Keras memberikan kinerja dan skalabilitas kekuatan industri: digunakan oleh organisasi dan perusahaan termasuk NASA, YouTube, atau Waymo.

Cara memanggil Keras di python model Neural Network:

from TensorFlow import keras

layers $=$ keras.layers

models $=$ keras.models

pada penelitian ini menggunakan TensorFlow versi 2.5.0

d) SCKIT LEARN - Optuna

Installasi optuna : \$pip install optuna

Parameter tuning model Neural Network yang digunakan pada optuna disajikan pada Tabel 2 berikut ini.

Tabel 2. Parameter Fungsi Objektif Optuna

\begin{tabular}{llll}
\hline No & Deskripsi Parameter & Kode & Rentang Nilai \\
\hline 1 & Banyak Layer & Layer & {$[1 . .2]$} \\
2 & Banyak Neuron di hidden layer 1 & $\mathrm{h} 1$ & {$[10 \ldots 500]$} \\
3 & Banyak Neuron di hidden layer 2 & $\mathrm{h} 2$ & {$[10 \ldots 500]$} \\
4 & Iterasi Maksimal & $\mathrm{i}$ & {$[10 \ldots 1000]$} \\
5 & Inisial Learning Rate & $\mathrm{ir}$ & {$[0.00001 \ldots 0.1]$} \\
6 & 'n_iter_no_change' & $\mathrm{ni}$ & {$[10 \ldots 30]$} \\
\hline
\end{tabular}

Dari parameter dan rentang nilai yang akan digunakan pada penelitian ini, dan selanjutnya akan di eksekusi sebagai nilai fungsi objektif pada Optuna.

3) Desain Pengujian dan Analisis

Kerangka alur penelitian ini adalah digambarkan pada Gambar 1 berikut ini. Model optimasi hyperparameter.

Adapun alur dari hyperparameter yang dibangun dapat dilihat seperti pada Gambar 2 berikut ini.

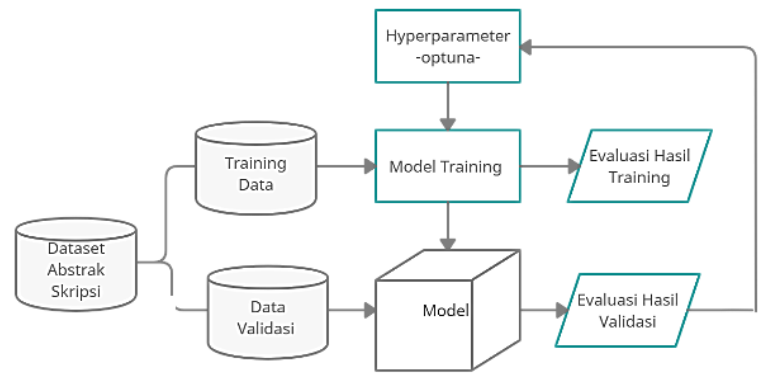

Gambar 2. Alur Klasifikasi dan Hyperparameter Tuning

Data dokumen abstrak yang telah dilabeli sesuai dengan tema kelas, selanjutnya akan dilakukan splitting antara data latih dan data uji. Konsep Neural Network apabila nilai loss lebih renda dari nilai akurasi maka hasil dianggap baik. Apabila nilai loss lebih tinggi disbanding akurasi maka diperluka optimasi dengan optuna. Pemodela Neural Network dibuat dengan library Keras-TensorFlow.

\section{HASIL DAN PEMBAHASAN}

Hasil penelitian untuk klasifikasi model Deep learning dengan algoritma Neural Network dengan memanfaatkan pemodelan TensorFlow mendapatkan hasil akurasi klasifikasi cukup baik. Pengujian dan validasi digunakan 
ISSN 2614-5278 (media cetak), ISSN 2548-8368 (media online)

Available Online at https://ejurnal.stmik-budidarma.ac.id/index.php/mib DOI 10.30865/mib.v5i3.3090

manual tuning. Akan tetapi dengan penambahan otomatisasi tuning dengan optuna yang dilakukan dengan model hyperparameter. Nilai akurasi menjadi meningkat. Berikut pembahasannya.

\begin{tabular}{|c|c|c|}
\hline \multirow{3}{*}{$\begin{array}{l}\text { In [9]: } \\
\text { Out [9]: }\end{array}$} & \multicolumn{2}{|c|}{ abstrak['Kelas'].value_counts() } \\
\hline & Aplikasi_Android & 38 \\
\hline & Data_Mining & 19 \\
\hline & RPL & 16 \\
\hline & SPK & 14 \\
\hline & Pengolahan_Citra_Digital & 8 \\
\hline & Sistem_Pakar & 8 \\
\hline & Name: Kelas, dtype: int64 & \\
\hline
\end{tabular}

\section{Gambar 3. Dataset}

Selanjutnya adalah membangun data latih dengan model split. Data latih yang digunakan secara acak dengan rasio 0.8 dari dataset. Adapun Teknik split yang digunakan ditampilkan pada Gambar 4 berikut ini.

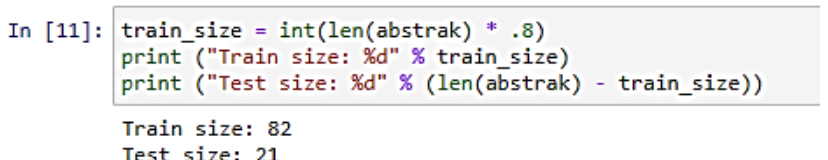

Gambar 4. Dataset

Data yang diperoleh dari pembagian secara split adalah seperti Nampak pada Gambar 4 di atas. Data latih atau train sebesar $80 \%=82$ dokumen. Sedangkan data uji atau Test $=21$ dokumen. Selanjutnya membangun model training proses build Keras TensorFlow. Sebagau berikut.

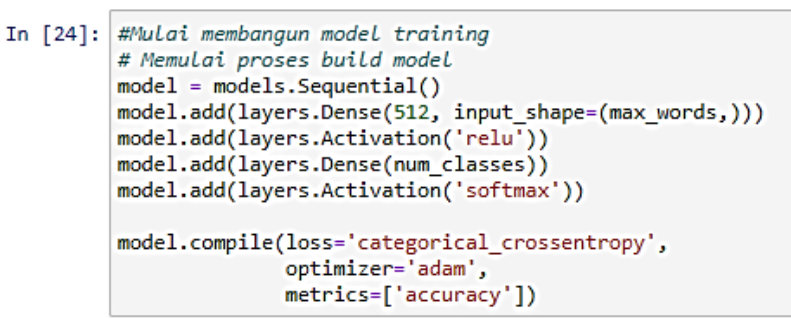

Gambar 5. Pemodelan TensoFlow Neural Network

Melakukan validasi data latih menggunakan batch_size $=12$, epochs $=2$, drop_ratio $=0.5$ dengan memperoleh hasil loss sebesar 0.6721 dan Accuracy sebesar 0.9589. dari validasi data latih tersebut dan selanjutnya dilakukan validasi data uji atau testing diperoleh hasil loss sebesar 1.0442 dan Accuracy sebesar 0.6190. hasil dapat dilihat pada Gambar 6 berikut ini.

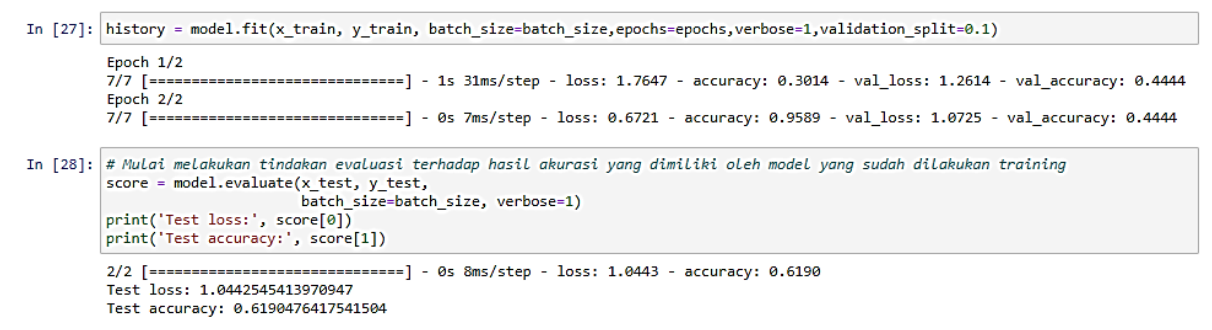

Gambar 6. Hasil Validasi Train dan Test

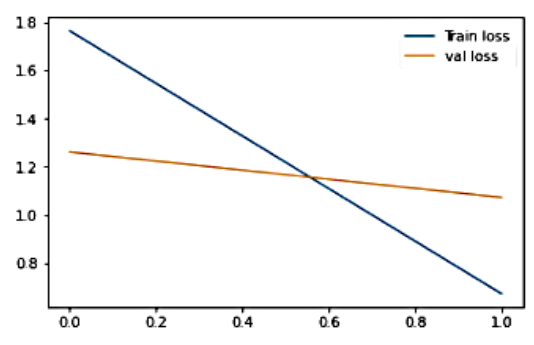

〈Figure size $432 \times 288$ with $\theta$ Axes>

Gambar 7. Visualisasi Train dan Test Validasi

Siti Mujilahwati, Copyright @2021, MIB, Page 1087 
ISSN 2614-5278 (media cetak), ISSN 2548-8368 (media online)

Available Online at https://ejurnal.stmik-budidarma.ac.id/index.php/mib DOI 10.30865/mib.v5i3.3090

Karena hasil Accuracy yang diperoleh tidak maksimal selanjutnya dilakukan pemodelan optimasi dengan scikit Learn model optuna. Implementasi di python adalah seperti terlihat pada gambar 8 berikut ini.

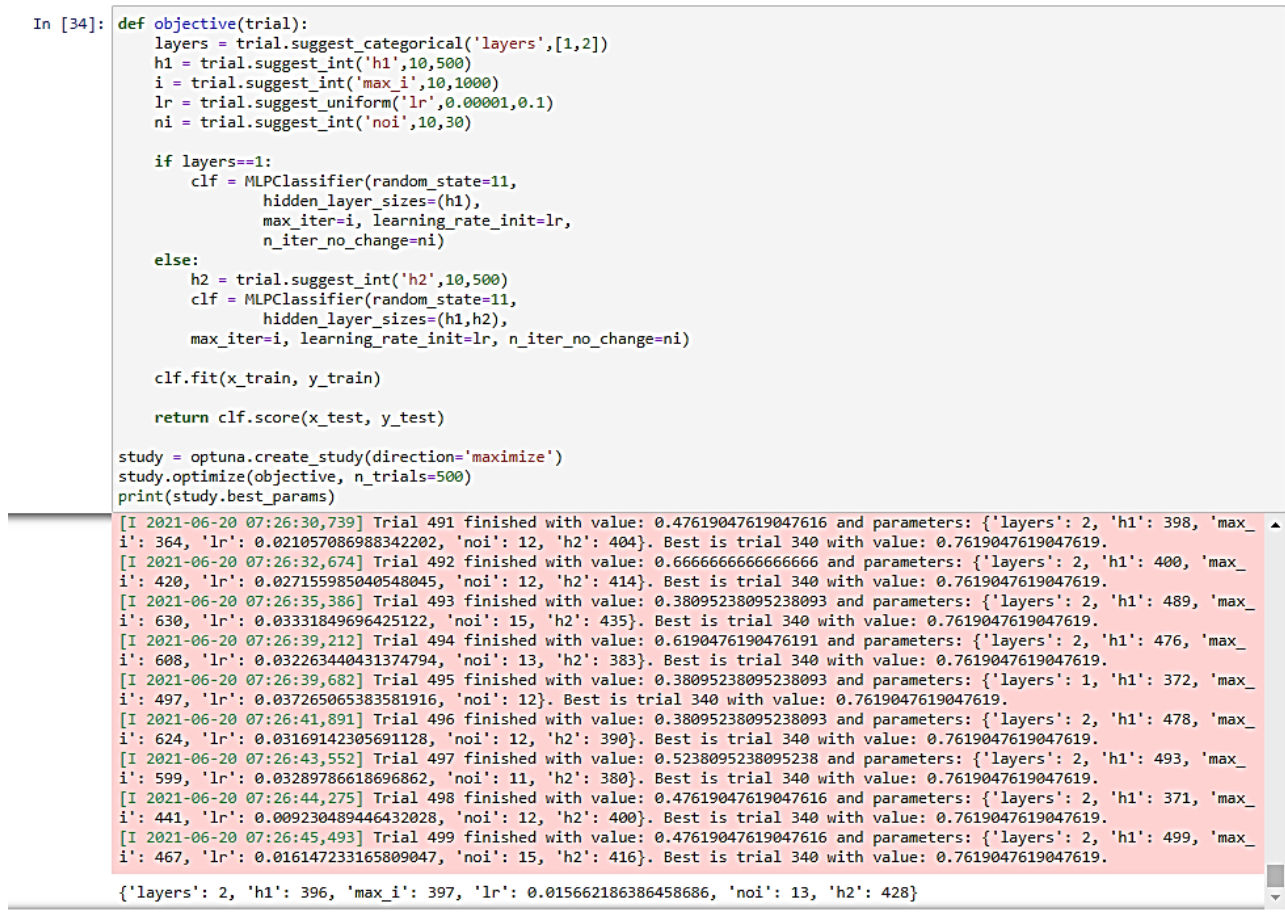

Gambar 8. Model dan Hasil Optuna

Setelah menambahkan hyperparameter untuk optimasi secara otomatis dapat dilihat hasil Accuracy meningkat menjadi $0.7619=76.19 \%$ dengan 'layers': 2 , 'h1': 396, 'max_i': 397, 'lr': 0.015662186386458686 , 'noi': 13, 'h2': 428. Menggunakan n_trial sebanyak 500 kali. Dengan demikian dapat simpulkan bahwa penambahan hyperparameter dengan model optuna dapat menambah atau meningkatkan akurasi secara otomatis tanpa harus melakukan setting epoch dan betc Size pada pemodelan di TensorFlow.

\section{KESIMPULAN}

Dari hasil pengujian klasifikasi atau validasi klasifikasi dokumen abstrak skripsi dengan menggunakan KerasTensorFlow di python maka disimpulkan bahwa model Neural Network yang diterapkan pada TensorFlow dengan menggunakan betch size sebesar 12 dan 2 epoch diperoleh nilai validasi sebesar 66.66\%. Selanjutnya dengan menambahkan hyperparameter otomatisasi meningkat dengan nilai hasil Accuracy sebesar $76.19 \%$.

\section{REFERENCES}

[1] A. D. Wattimena, "Analisis Sentimen Teks Bahasa Indonesia Pada Media Sosial Menggunakan Algoritma Convolutional Neural Network (Studi Kasus : E-Commerce),” p. 248, 2018.

[2] D. Yuliana and C. Supriyanto, "Klasifikasi Teks Pengaduan Masyarakat Dengan Menggunakan Algoritma Neural Network," p. 27, 2019.

[3] A. Peryanto, A. Yudhana, and R. Umar, "Rancang Bangun Klasifikasi Citra Dengan Teknologi Deep learning Berbasis Metode Convolutional Neural Network," Format J. Ilm. Tek. Inform., vol. 8, no. 2, p. 138, Feb. 2020, doi: 10.22441/format.2019.v8.i2.007.

[4] Slamet Fifin Alamsyah, "Implementasi Deep Learning Untuk Klasifikasi Tanaman Toga Berdasarkan Ciri Daun Berbasis Android," Ubiquitous Comput. Its Appl. J., pp. 113-122, Dec. 2019, doi: 10.51804/ucaiaj.v2i2.113-122.

[5] P. Cen, K. Zhang, and D. Zheng, "Sentiment Analysis Using Deep learning Approach," J. Artif. Intell., vol. 2, no. 1, pp. 17-27, 2020, doi: 10.32604/jai.2020.010132.

[6] K. Devipriya, D. Prabha, V. Pirya, and S. Sudhakar, "Deep learning Sentiment Analysis For Recommendations In Social Applications," vol. 9, no. 01, p. 4, 2020.

[7] O. Habimana, Y. Li, R. Li, X. Gu, and G. Yu, "Sentiment analysis using Deep learning approaches: an overview," Sci. China Inf. Sci., vol. 63, no. 1, p. 111102, Jan. 2020, doi: 10.1007/s11432-018-9941-6.

[8] A. Hassan and A. Mahmood, "Deep learning approach for sentiment analysis of short texts," in 2017 3rd International Conference on Control, Automation and Robotics (ICCAR), Nagoya, Japan, Apr. 2017, pp. 705-710. doi: 10.1109/ICCAR.2017.7942788.

[9] M. Heikal, M. Torki, and N. El-Makky, "Sentiment Analysis of Arabic Tweets using Deep Learning," Procedia Comput. Sci., vol. 142, pp. 114-122, 2018, doi: 10.1016/j.procs.2018.10.466. 
ISSN 2614-5278 (media cetak), ISSN 2548-8368 (media online)

Available Online at https://ejurnal.stmik-budidarma.ac.id/index.php/mib

DOI 10.30865/mib.v5i3.3090

[10] R. R. Santoso, R. Megasari, and Y. A. Hambali, "Implementasi Metode Machine Learning Menggunakan Algoritma Evolving Artificial Neural Network Pada Kasus Prediksi Diagnosis Diabetes," p. 13.

[11] H. Juwiantho, E. I. Setiawan, J. Santoso, and M. H. Purnomo, "Sentiment Analysis Twitter Bahasa Indonesia Berbasis Word2vec Menggunakan Deep Convolutional Neural Network," p. 8.

[12] B. P. Putra, B. Irawan, and S. Si, "Deteksi Ujaran Kebencian Dengan Menggunakan Algoritma Convolutional Neural Network Pada Gambar," p. 8.

[13] A. M. Zamani and J. A. R. Hakim, "Implementasi Algoritma Genetika pada Struktur Backpropagation Neural Network untuk Klasifikasi Kanker Payudara," vol. 1, no. 1,p. 6, 2012.

[14] I. Ali and L. Sularto, "Optimasi Parameter Artificial Neural Network Menggunakan Algoritma Genetika Untuk Prediksi Kelulusan Mahasiswa,” J. ICT Inf. Commun. Technol., vol. 18, no. 1, pp. 54-59, Aug. 2019, doi: 10.36054/jictikmi.v18i1.52.

[15] M. Badrul, "Optimasi Neural Network Dengan Algoritma Genetika Untuk Prediksi Hasil Pemilukada,” . P, p. 14.

[16] R. Dina, "Optimasi Backpropagation Neural Network Menggunakan Metode Algoritma Genetika Dalam Memprediksi Jumlah Pengangguran," p. 149.

[17] Electrical Engineering Universitas Udayana, N. Widiangga Gautama, A. Dharma, and M. Sudarma, "Analisis Metode Rbf-Nn Dengan Optimasi Algoritma Genetika Pada Peramalan Mata Uang Eur/Usd," Maj. Ilm. Teknol. Elektro, vol. 15, no. 2, pp. 107-114, Dec. 2016, doi: 10.24843/MITE.1502.16.

[18] A. Kusnadi and J. Pratama, "Implementasi Algoritma Genetika dan Neural Network Pada Aplikasi Peramalan Produksi Mie (Studi Kasus : Omega Mie Jaya)," p. 5.

[19] K. Willems, "Jupyter Notebook Tutorial: The Definitive Guide." https://www.datacamp.com/community/tutorials/tutorial-jupyter-notebook 